\title{
Distribution Pattern of Seahorse Species (Genus: Hippocampus) in Tamilnadu and Kerala Coasts of India
}

\author{
Aaron Premnath LIPTON ${ }^{1}$, Muthusamy THANGARAJ ${ }^{2 *}$ \\ ${ }^{1}$ Marine Biotechnology Laboratory, Vizhinjam Research Centre of Central Marine Fisheries \\ Research Institute, Vizhinjam, Thiruvananthapuram, Kerala- 695521, India \\ ${ }^{2}$ Centre for Advanced Study in Marine Biology, Annamalai University, Parangipettai- 608 \\ 502, TamilNadu, India; coralholder@yahoo.com (*corresponding author)
}

\begin{abstract}
The survey along the Tamilnadu and Kerala coats of India reveled that six species of seahors (Hippocampus fuscus, H. kelloggi, H. kuda, $H$. histrix, $H$. mohnikei and $H$. trimaculatus) were distributed with different density. Out of the six species, $H$. fuscus, $H$. kuda and $H$. trimaculatus, were the commonly available in all the observed areas. In Palk Bay, H. kuda was the dominant species constituting $49.10 \%$ of the total seahorses encountered. Hippocampus trimaculatus was the second dominant species which accounting $39.28 \%$. The Gulf of Mannar region also most abounded with H. kuda (68.98\%) followed by H. trimaculatus (20.80\%), H. fuscus (9.80\%), H. kelloggi (2.23\%) and H. histrix (0.37\%). In Kerala coast, H. trimaculatus was the dominant species (79.68\%) followed by H. kuda (9.89\%), H. kelloggi (8.33\%) and H. fuscus (2.08\%). To infer the variation of six seahorse species, the morphometric and meristic characters were analysed. The important morphometric and meristic characters are trunk rings, tail rings, pectoral and dorsal fin rays, trunk length, tail length, coronet height, head length, snout length, snout depth and head depth. Variations in overall body shape, relative snout length, coronet height, number of tail ring was sufficient to separate the specimens to Hippocampus fuscus, H. kelloggi, H. kuda, H. histrix, H. mohnikei and $H$. trimaculatus. The species density and diversity depends on the habitat and biogeography of those areas. Majority of seahorse fishing in Tamilnadu was by shrimp trawl, by-catch and very few target catch by divers also seen in some villages in Palk Bay and Gulf of Mannar region. The shrimp trawl by-catch only bringing more $H$. trimaculatus than the other seahorse species in Kerala coasts.
\end{abstract}

Keywords: distribution pattern, Gulf of Mannar, morphometric, meristic variation, Palk Bay, seahorse, South Malabar

\section{Introduction}

Seahorses are one of the members of the family Syngnathidae and thirty three species come under the single genera, Hippocampus (Dawson, 1980; Lourie et al., 2004). They are found throughout the world in shallow, coastal tropical and temperate waters and are more abundant in the Indo-Pacific region (Lourie et al., 1999). They are distributed in high density along the China coast among seaweed and in seagrass from Vietnam to Korea (Lourie et al., 1999). Based on the tentative assessment, Vincent (1996) observed that the seas adjacent to China might contain about seven species, although their taxonomy remained confused. In north-east countries like Philippines and Vietnam they often found in seagrass beds, mangrove, coral reef areas and also in estuaries. Among all seahorses, $H$. trimaculatus was the most common species on sale in Vietnam markets (Vincent, 1996).

The unclear taxonomy of seahorse is due to the limited morphological variation among species, poor type descriptions, independent designation of the same name for different species, and the ability to changing their body colour and growing skin filaments to mach their surroundings (Lourie et al., 1999). As per Lourie et al. (1999), the standard morphometric and meristic character analysis may clear the taxonomical ambiguity. They are: trunk rings, tail rings, pectoral and dorsal fin rays, trunk length, tail length, coronet height, head length, snout length, snout depth and head depth.

Seahorses have been traded along with pipefishes as dried form to East Asian countries for medicinal purpose (Martin-Smith et al., 2003). Now, seahorse fishing and trading is restricted in all over the world because of their declining population size and the entire seahorse species are listed in scheduled (Baillie and Groombridge, 1996). In India the Ministry of Environment and Forests banned the export permits for all Syngnathids from the year 2001 and declared them under Schedule I of the Indian Wildlife Protection Act, 1972 (Sreepada et al., 2002). In India, Marichamy et al. (1993) tentatively reported that two species (H. kuda and H. trimaculatus) was found along the Palk Bay. Later on, Lipton and Thangaraj (2002) made a detailed study of these species and one more species was added (H. fuscus) in Palk Bay coastal region. More recent- 
ly, Murugan et al. (2008) reported five species of seahorses along the South east coast of India. In the present paper, it is described the morphometric and meristic characters of seahorses, and the survey shows the distribution pattern along the Tamilnadu and Kerala states of India.

\section{Materials and methods}

\section{Seahorse survey}

For the seahorse resource assessment studies, Palk Bay, Gulf of Mannar in Tamilnadu and Malabar coast in Kerala was selected and the details are given in Tab. 1. Generally seahorses are caught as by-catch by small trawlers, targeting the shrimp in both the states. The data such as the number, types of boats and duration of operation were collected by interviewing the respective area fisherfolk. Shore seines are used in the shallow coastal region at 2-3 $\mathrm{m}$ depth. Country trawl nets are operated at 3-6 $\mathrm{m}$ depth. The shrimp trawlers are operated at $15-50 \mathrm{~m}$ depth and targeting shrimps. Data collections were made from all the three regions on monthly basis over a period of four years from June 2003 to May 2007. The by-catch of seahorses from all the boats in each area was counted and additional data also gathered from the primary traders in the respective areas.

\section{Morphological characters and species identification}

All the wet specimens were obtained as by-catch by small off shore trawlers, targeting the shrimp and the dried specimens were got from small traders in the repective stations. No seahorse was caught especially for this work. With the reference of the identification book (Lourie et al., 1999) the specimens were sorted into six apparent morphotypes as Hippocampus fuscus, H. kelloggi, H. kuda, $H$. histrix, H. mohnikei and H. trimaculatus. Morphometric measurements were taken using a digital caliper (Mi-
Tab. 1. Seahorse survey area in Tamilnadu and Kerala states

\begin{tabular}{cccc}
\hline $\begin{array}{c}\text { Survey } \\
\text { area }\end{array}$ & Geographical location & $\begin{array}{c}\text { Distance } \\
\text { covered }\end{array}$ & $\begin{array}{c}\text { Nature of } \\
\text { substratum }\end{array}$ \\
\hline Palk Bay & $\begin{array}{c}\text { Rameshwaram }\left(9^{\circ} 17^{\prime} \mathrm{N} \text {; }\right. \\
\begin{array}{c}\left.79^{\circ} 18^{\prime} \mathrm{E}\right) \text { to Point calimer } \\
\left(10^{\circ} 12^{\prime} \mathrm{N} ; 79^{\circ} 52^{\prime} \mathrm{E}\right)\end{array}\end{array}$ & $\sim 250 \mathrm{~km}$ & $\begin{array}{c}\text { seagrass, } \\
\text { sponges, corals }\end{array}$ \\
$\begin{array}{c}\text { Kanyakumari }\left(8^{\circ} 05^{\prime} \mathrm{N} \text {; }\right. \\
\text { Gulf of }\end{array}$ & $\begin{array}{c}\text { Kannar } \\
\left.77^{\circ} 34^{\prime} \mathrm{E}\right) \text { to Rameshwaram } \\
\left(9^{\circ} 17^{\prime} \mathrm{N} ; 79^{\circ} 18^{\prime} \mathrm{E}\right)\end{array}$ & $\sim 325 \mathrm{~km}$ & $\begin{array}{c}\text { seagrass, } \\
\text { sponges, corals, } \\
\text { seaweeds }\end{array}$ \\
$\begin{array}{c}\text { Malabar Calicut }\left(11^{\circ} 21^{\prime} \mathrm{N} ; 75^{\circ} 54^{\prime} \mathrm{E}\right) \text { to } \\
\text { coast }\end{array}$ & $\sim 400 \mathrm{~km}$ & $\begin{array}{c}\text { Vponges, } \\
\text { gorgonids }\end{array}$ \\
\hline
\end{tabular}

tutoyo, Japan) with $0.1 \mathrm{~mm}$ accuracy. The meristic counts were counted under a dissection microscope and the values were confirmed by three time counting. All the morphometric measurements and counted characters were strictly followed Lourie et al. (1999) protocol.

\section{Results}

\section{Morphological characters and species identification}

During the study period, six species of seahorses (Fig. 1) were recorded from the observation centers. Variation in overall body shape, relative snout length, coronet height, number of tail ring was sufficient to separate the specimens to Hippocampus fuscus, $H$. kelloggi, $H$. kuda, $H$. histrix, $H$. mohnikei and $H$. trimaculatus (Fig. 1). The basic morphometric and meristic statistics are given in Tab. 2, the abbreviations are given in Lourie et al. (1999).

\section{Percentage distribution}

The distribution of the above six species was not uniform in all the sites surveyed. The percentages of species availability in three locations are given in Tab. 3. Only one specimen of $H$. mohnikei was observed during this study

Tab. 2. Basic morphometric and meristic characteristics of five seahorse species

\begin{tabular}{|c|c|c|c|c|c|}
\hline Morphometric & Hippocampus kuda & H. trimaculatus & H. fuscus & H. kelloggi & H. histrix \\
\hline $\mathrm{SL}(\mathrm{mm})($ mean $\pm \mathrm{SD})$ & $119.6 \pm 14.03$ & $127.68 \pm 24.45$ & $130.32 \pm 20.21$ & $191.66 \pm 35.98$ & $135.60 \pm 24.45$ \\
\hline $\operatorname{TrL}(\% \mathrm{SL})$ & $27.75 \pm 04.22$ & $26.26 \pm 05.90$ & $29.88 \pm 05.23$ & $30.13 \pm 05.56$ & $28.25 \pm 05.80$ \\
\hline $\mathrm{TaL}(\% \mathrm{SL})$ & $59.49 \pm 06.47$ & $55.56 \pm 12.28$ & $52.57 \pm 08.04$ & $57.39 \pm 08.92$ & $57.52 \pm 12.23$ \\
\hline $\mathrm{HL}(\% \mathrm{SL})$ & $17.15 \pm 02.18$ & $15.95 \pm 03.41$ & $15.10 \pm 02.83$ & $19.04 \pm 05.09$ & $17.85 \pm 04.51$ \\
\hline $\operatorname{SnL}(\% \mathrm{HL})$ & $52.25 \pm 08.02$ & $52.38 \pm 12.17$ & $53.96 \pm 07.72$ & $55.01 \pm 15.34$ & $54.38 \pm 11.12$ \\
\hline $\mathrm{CH}(\% \mathrm{HD})$ & $81.08 \pm 12.69$ & $74.68 \pm 20.10$ & $74.30 \pm 17.33$ & $75.52 \pm 15.46$ & $75.65 \pm 18.10$ \\
\hline $\mathrm{HD}(\% \mathrm{HL})$ & $59.50 \pm 07.50$ & $63.23 \pm 14.97$ & $66.05 \pm 08.33$ & $93.37 \pm 12.94$ & $65.25 \pm 15.27$ \\
\hline $\mathrm{SnD}(\% \mathrm{SnL})$ & $28.91 \pm 04.01$ & $28.39 \pm 06.18$ & $30.22 \pm 07.15$ & $24.90 \pm 06.17$ & $30.32 \pm 07.12$ \\
\hline TD4 (\%TD9) & $74.71 \pm 11.48$ & $71.79 \pm 12.82$ & $67.21 \pm 10.82$ & $69.59 \pm 06.82$ & $73.59 \pm 10.82$ \\
\hline TW (\%SPW) & $75.31 \pm 12.76$ & $94.67 \pm 27.71$ & $90.13 \pm 15.74$ & $75.34 \pm 04.07$ & $95.57 \pm 23.61$ \\
\hline DL (\%TrL) & $27.13 \pm 05.03$ & $29.39 \pm 05.96$ & $23.74 \pm 04.36$ & $25.24 \pm 03.98$ & $31.39 \pm 05.12$ \\
\hline PL (\%HD) & $34.07 \pm 07.20$ & $34.93 \pm 11.41$ & $33.38 \pm 08.84$ & $39.09 \pm 08.85$ & $33.83 \pm 10.21$ \\
\hline \multicolumn{6}{|l|}{ Meristic } \\
\hline $\operatorname{TrR}$ & $11-12$ & $11-12$ & $11-12$ & $11-12$ & $11-12$ \\
\hline $\mathrm{TaR}$ & $34-39$ & $34-44$ & $32-36$ & $39-41$ & $34-36$ \\
\hline PFR & $15-18$ & $17-18$ & $14-16$ & $17-19$ & $17-20$ \\
\hline DFR & $17-18$ & $19-22$ & $14-17$ & $17-19$ & $15-18$ \\
\hline
\end{tabular}




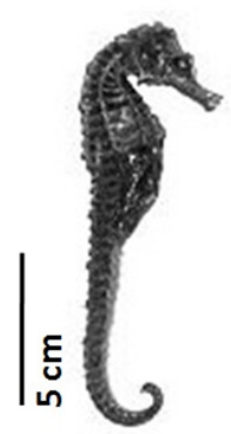

A

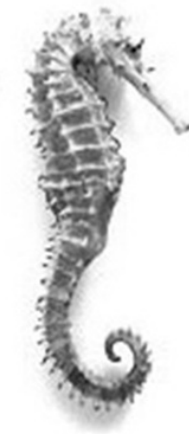

B

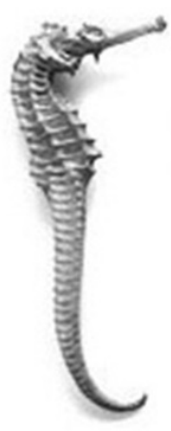

C

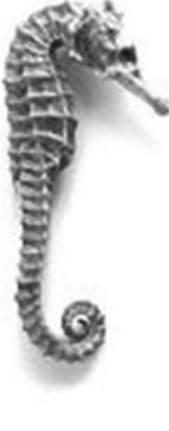

D

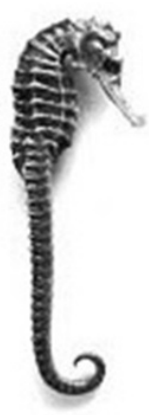

E

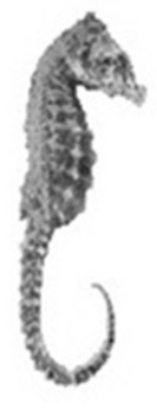

$\mathrm{F}$

Fig. 1. Seahorse species (A) Hippocampusfuscus, (B) H. histrix, (C) H. kelloggi, (D) H. kuda, (E) H. trimaculatus, (F) H. mohnikei

from Palk Bay. In this regard, this species was excluded in percentage calculation of other species in respect to different area. In Palk Bay, H. kuda was the dominant species constituting $49.10 \%$ of the total seahorses encountered. Hippocampus trimaculatus was the second dominant species which accounting $39.28 \%$. The Gulf of Mannar region also most abounded with $H$. kuda (68.98\%) followed by H. trimaculatus (20.80\%), H. fuscus (9.80\%), H. kelloggi (2.23\%) and H. histrix (0.37\%). In Kerala coast, H. trimaculatus was the dominant species $(79.68 \%)$ followed by $H$. kuda (9.89\%), H. kelloggi (8.33\%) and H. fuscus (2.08\%).

Tab. 3. Percentage (\%) distribution of seahorse species in Tamilnadu and Kerala states of India

\begin{tabular}{ccccc}
\hline \multirow{2}{*}{$\begin{array}{c}\text { Sl. } \\
\text { No }\end{array}$} & \multirow{2}{*}{ Species } & \multicolumn{2}{c}{ Tamilnadu } & \multirow{2}{*}{ Kerala } \\
\cline { 3 - 4 } & & Palk Bay & Gulf of Mannar & \\
\hline 1. & Hippocampusfuscus & 11.60 & 9.80 & 2.08 \\
2. & H. histrix & 0.00 & 0.37 & 0.00 \\
3. & H. kelloggi & 0.00 & 2.23 & 8.33 \\
4. & H. kuda & 49.10 & 68.98 & 9.89 \\
5. & H. trimaculatus & 39.28 & 20.80 & 79.68 \\
\hline
\end{tabular}

\section{Discussion}

Detailed morphometric analysis was sufficient to distinguish this four seahorse morphotypes, although intergroup distance was sometimes small. In this article we have highlighted the characters which permit species identification by eye and this may facilitate practical application in this field. Hippocampus fuscus could be distinguished from the other two related Indian seahorses, viz., H. borboriensis and $H$. kuda. The morphometric characteristics of $H$. borboniensis were studied earlier by Salin et al. (2005). Hippocampus borboniensis possesses a relatively larger head and two prominent eye spines on the head. In H. fuscus there is no eye spine. Hippocampus borboniensis has a shallower body than that of $H$. fuscus. Hippocampus kuda also differs from $H$. fuscus by having larger body size and backward turned coronet. In $H$. fuscus, the coronet is slightly raised without any backward curve. In $H$. fuscus the snout depth also differs from that of $H$. kuda. In $H$. fuscus, the snout depth is somewhat higher $(30.22 \pm 7.15 \%$ of snout length) than in H. kuda $(28.91 \pm 4.01 \%$ of the snout length). When the dorsal finbase length (DL) and pectoral finbase length (PL) were compared, $H$. fuscus has been found to be lower $(23.74 \pm 4.36 \%$ of trunk length) than H. kuda DL (27.13 $\pm 5.03 \%$ of trunk length). In H. fuscus, the PL is smaller $(33.38 \pm 8.84 \%$ of head depth) than that of $H$. kuda (34.07 $\pm 7.20 \%$ of head depth). In H. fuscus, the head depth is higher $(66.05 \pm 8.33 \%$ of head length $)$ than $H$. kuda (59.50 $\pm 7.50 \%$ of head length). Though $H$. bippocampus is considered to be similar to $H$. fuscus, it is restricted only to the European waters.

Hippocampus kelloggi is the largest seahorse species found in the Indian waters. Fish Base (Froese and Pauly, 2012) considered the distribution of $H$. kelloggi as of Indo-Pacific and listed the same as a possible Indian species. Hippocampus kelloggi can be distinctly differs from other morphologically similar species such as $H$. borboniensis, $H$. fuscus, $H$. ingens, $H$. kuda and H. spinosissimus. Hippocampus kelloggi has five elevated short coronet spines and a plate in front of the coronet, but in the case of $H$. borboniensis, the coronet has five rounded knobs and no plate in front of the coronet as per Lourie et al. (1999). Tail rings are also higher (39-41) in $H$. kelloggi than the $H$. borboniensis (34-38). Hippocampus fuscus differs from $H$. kelloggi by having less number of tail rings (33-37), dorsal fin rays (14-17) and pectoral fin rays (14-16) (Lourie et al., 1999). In H. kelloggi, the pectoral and dorsal finrays count between 17-19 and 17-19 respectively. In H. fuscus, the tail length is much lower $(52.39 \pm 8.04 \%$ of total body length) than $H$. kelloggi, where it was $57.39 \pm 8.92$ (\% of total body length). Hippocampus kelloggi is distinctly differs from H. fuscus in snout and head length. In H. kelloggi, the snout length is $55.01 \pm 15.34$ (\% of head length) and head length is $19.04 \pm 5.05 \%$ of the total body length but in $H$. fuscus, the snout length is only $53.96 \pm 7.72$ (\% of head length) and the head length is $15.10 \pm 2.83 \%$ of total body length. In $H$. fuscus, the coronet is somewhat more 
smooth and uncurved than in H. kelloggi. Hippocampus ingens also has nearly the same morphological traits as $H$. kelloggi, but differs by having highly elevated coronet and less number (37-38) of tail rings. It was reported to occur only in the Caribbean Sea (Lourie et al., 1999). Hippocampus kelloggi has a deep head of $93.37 \pm 12.94 \%$ in head length compared to other Indian seahorse species. The head depth of $H$. fuscus and $H$. kuda measures 66.05 \pm 8.33 and $59.50 \pm 7.50 \%$ of the head length respectively. The morphometric and meristic traits of $H$. kuda are distinctly differs from $H$. kelloggi. The total body length and trunk length of $H$. kuda is $119.6 \pm 14.03 \mathrm{~mm}$ and 27.75 \pm 4.22 (\% of total body length) respectively, whereas in $H$. Kellogi, it is $191.66 \pm 35.98 \mathrm{~mm}$ and $30.13 \pm 5.65$ (\% of total body length) respectively. And also in $H$. kuda, the tail is longer $(59.49 \pm 6.47 \%$ of total body length) H. kel$\operatorname{loggi}(57.39 \pm 8.92 \%$ of total body length).

Hippocampus kuda can be distinguished from other seahorse species belonging the $H$. kuda complex as shown below. Hippocampus algiricus has double eye and cheek spines, has a restricted geographical distribution, and is found in the Eastern Atlantic off the west coast of Africa (Lourie et al., 1999). There is no possibility of its occurrence in the Indian waters. Hippocampus reidi with lesser tail rings, larger coronet and double eye spines and reported from Western Atlantic Ocean only (Lourie et al., 1999). Hippocampus fuscus is often misidentified as H. kuda. Hippocampus kuda has a larger body size and backward turned coronet. But $H$. fuscus's coronet is slightly raised, smooth and never bent backward. In H. kuda, the snout depth is lesser $(28.91 \pm 4.01 \%$ of snout length) than $H$. fuscus (30.22 $\pm 7.15 \%$ of snout length). In $H$. kuda, the dorsal finbase length $(\mathrm{DF})$ is higher $(27.13 \pm 5.03 \%$ of trunk length) than $H$. fuscus (23.74 $\pm 4.36 \%$ of trunk length). In $H$. kuda the pectoral finbase length (PF) is also higher (34.07 $\pm 7.20 \%$ of head depth) than H. fuscus $(33.38 \pm$ $8.84 \%$ of head depth). The head depth of $H$. kuda is lower (59.50 $\pm 7.50 \%$ of head length) when compared with $H$. fuscus ( $66.05 \pm 8.33 \%$ of head length).

The three spotted seahorse, $H$. trimaculatus is widely distributed throughout South India. Though they are deepwater in habitat, they brought to shore mainly by the trawlers. This species also included as one of the members of $H$. kuda complex. The other similar species include $H$. fisheri, $H$. fuscus and $H$. kuda. Since all of them possess several common characteristics, some specific features are used to distinguish each one. Hippocampus fisheri has double cheek and eye spines and two prominent nose spines, whereas in H. trimaculatus, there is a single hooklike cheek spine, sharp hook-like eye spines and no nose spines. In H. fisheri, enlarged spines are scattered throughout the body, but in $H$. trimaculatus, the spines are very small. Hippocampus fisheri has fewer tail rings (37-38), dorsal (17-18) and pectoral finrays (13-16) than in $H$. trimaculatus. Moreover, $H$. fisheri is found only in Hawaii waters (Lourie et al., 1999). Hippocampus trimaculatus has very low coronet, but five sharp hook-like spines at the top. But in $H$. fuscus the coronet is slightly raised and no hook-like structure on the top of the coronet. In H. fuscus, the snout length and depth are much shorter than $H$. trimaculatus. In $H$. fuscus the tail length is much shorter ( $53.57 \pm 8.04 \%$ of total body length) than $H$. trimaculatus (55.56 $\pm 12.28 \%$ of total body length). Hippocampus fuscus has longer trunk $(29.88 \pm 5.23 \%$ of total body length) than that of $H$. trimaculatus $(26.26 \pm 5.90 \%$ of total body length). Hippocampus kuda differs from $H$. trimaculatus in the following respects: Hippocampus kuda has larger body size and slightly backward turned coronet, unlike in $H$. trimaculatus. The tail of $H$. kuda is much longer $(59.49 \pm$ $6.47 \%$ of total body length) than that of $H$. trimaculatus (55.56 $\pm 12.28 \%$ of total body length). The head and coronet of $H$. kuda are also much longer, $(17.15 \pm 2.18 \%$ of total body length; $81.08 \pm 12.69 \%$ of head depth) than $H$. trimaculatus $(15.95 \pm 3.41 \%$ of total body length; 74.68 $\pm 20.10 \%$ of head depth). Both H. fuscus and H. kuda are differing from $H$. trimaculatus by the absence of large dark spots on the dorso-lateral surface of the first, fourth and seventh trunk rings. These species specific traits easily distinguish $H$. trimaculatus from the other similar species.

The Syngnathids are usually associated with vegetated or other structurally complex habitats (Lourie et al., 1999; Pollard, 1984). However, specific habitat associations have been reported for H. bargibanti (Lourie et al., 1999). Different species of Syngnathids often co-exist in the seagrass beds (Curtis and Vincent, 2005; Kendrick and Hyndes, 2003). In India, the common and widely distributed species are $H$. kuda, H. fuscus and H. trimaculatus. Along the Palk Bay coast, the shrimp trawl by-catch generally brings in higher quantities of $H$. kuda. In the Palk Bay area, four species of seahorses have been recorded. H. mohnikei may not be an Indian species and it might be come to Indian coast by drifting or by water currents (Thangaraj and Lipton, 2007). Among the three species, H. trimaculatus is to be found more in the deeper waters ( $>50$ feet) among sponges, soft corals and sandy bottoms than in the seagrass beds. This confirms the observations of Lourie $e t$ al. (1999) and this species mostly occurring in deeper waters $(>15 \mathrm{~m})$. Earlier survey showed that $H$. kuda was the dominant species in this area (Murugan et al., 2008) and it is confirmed by the present survey. Except $H$. mohnikei all the five species could be collected from Gulf of Mannar whereas $H$. kelloggi and H. histrix were not found in Palk Bay region.

Generally seahorses are patchily distributed and occur at low densities throughout the world (Foster and Vincent, 2004). In Gulf of Mannar, as like in Palk Bay, H. kuda was the dominant species. Earlier reports also suggest that H. kuda was the dominant species in the Gulf of Mannar (Lipton and Thangaraj, 2002). But, Murugan et al. (2008) reported that $H$. trimaculatus was the dominant species in this area. Hippocampus kelloggi and H. histrix were found exclusively in the Gulf of Mannar, and absent in the Palk 
24

Bay. Of these five species, $H$. histrix was found in very low density in India, also occurs only in very deep sea. Lourie et al. (1999) reported that $H$. kelloggi and $H$. histrix prefer deeper waters than shallow seagrass beds.

Recently Salin et al. (2005) reported that in Kerala coast, the shrimp trawl by-catch of seahorses was dominated by $H$. trimaculatus. The present observation confirms Salin's report, there $H$. trimaculatus contributes a major share in the total seahorse by-catch. The occurrence of $H$. fuscus observed in Kerala coast is the first time report. The contribution of this species is extremely poor in this area; this is possibly due to the lack of suitable substratum (seagrass bed) for this shallow water species. Hippocampus histrix was not found in Malabar and also suggesting due to the geographical rigidity in their occurrence.

\section{Conclusion}

The morphometric and meristic character standardization is essential for conservation purpose; enabling effective communication among fishers, traders, scientists, fisheries officials and custom officials. Taxonomic confusion complicates assessment of species conservation status, forcing unnecessary listing of synonyms in IUCN Red List of Threatened Species and greatly increasing the possibility of omitting species definitions is growing rapidly in India. From this study it clearly denotes that $H$. fuscus, $H$. kuda and $H$. trimaculatus, are the commonly distributed species in all the three observed areas. The shrimp trawl by-catch was bringing abundant $H$. trimaculatus than the other species in Kerala coast. In the context of the current ban on seahorse exploitation and trade in India, it is important to monitor their populations regularly from all major habitats to determine their progressive revival to the optimum level.

\section{Acknowledgements}

The authors would like to thank The Director CMFRI and The Dean, Faculty of Marine Sciences, Annamalai University for the facilities and encouragements. They are also thankful to Ministry of Environment and Forests, Govt. of India, New Delhi for funding.

\section{References}

Baillie J, Groombridge B (1996). IUCN red list of threatened animals. Gland, Switzelland: IUCN (World Conservation Union)

Balasubramanian R (2002). Studies on seahorses with special reference to Hippocampus kelloggi (Jordan and Snyder, 1902) in Southeast coast of India. Ph.D. thesis. Annamalai University, India, $124 \mathrm{p}$.
Curtis JMR, Vincent ACJ (2005). Distribution of sympatric species along a gradient of habitat complexity in a seagrass dominated community. Mar Ecol Prog Ser 291:81-91.

Dawson CE (1980). Indo-Pacific Pipefishes (Redsea to the Americas) Gulf Coast Research Laboratory, Ocean Spring, Mississippi, USA, $230 \mathrm{p}$.

Foster SJ, Vincent ACJ (2004). Life history and ecology of seahorse: Implication for conservation and management. J Fish Biol 65:1-61.

Froese R, Pauly D (2012). Fish Base. Available at http://www. fishbase.org

Kendrick AJ, Hyndes GA (2003). Patterns in the abundance and size- distribution of syngnathid fishes among habitats in a seagrass-dominated marine environment. Estuarine Coastal Shelf Sci 57:631-640.

Lipton AP, Thangaraj M (2002). Present status of seahorse fishing along the Palk Bay coast of Tamilnadu. Mar Fish Info Serv Tech Ext Seri 174:5-8.

Lourie SA, Vincent ACJ, Hall HJ (1999). Seahorses: an identification guide to the world's species and their conservation. Project Seahorse, London, U.K, 214 p.

Lourie SA, Foster SJ, Cooper EWT, Vincent ACJ (2004). A guide to the identification of seahorses. Project Seahorse and TRAFFIC North America, Washington DC, University of British Columbia, $114 \mathrm{p}$.

Marichamy R, Lipton AP, Ganapathy, Ramalingam JR (1993). Large-scale exploitation of seahorse (Hippocapus kuda) along the Palk Bay coast of Tamilnadu. Mar Fish Info Serv Tech Ext Seri 119:17-20.

Martin-Smith KM, Lam TF, Lee SK (2003). Trade in pipehorses Solegnathus spp for traditional medicine in Hong Kong. TRAFFIC Bull 19:139-148.

Murugan A, Dhanya S, Rajagopal S, Balasubramanian T (2008). Seahorses and pipe fishes of the Tamil Nadu coast. Curr Sci 95:253-260.

Pollard DA (1984). A review of ecological studies on seagrassfish communities, with particular reference to recent studies in Australia. Aquat Bot 18:3-42.

Salin KR, Yohannan TM, Mohankumaran Nair C (2005). Fisheries and trade of seahorses, Hippocampus spp., in southern India. Fish Manag Ecol 12:269-273.

Sreepada RA, Desai UM, Naik S (2002). The plight of Indian seahorses: Need for conservation and management. Curr Sci 82:377-378.

Thangaraj M, Lipton AP (2007). Occurrence of the Japanese seahorse Hippocampus mohnikei Bleeker 1854 from the Palk Bay coast of South-eastern India. J Fish Biol 70:310-312.

Vincent ACJ (1996). The international trade in seahorses. TRAFFIC International. Cambridge, U.K, 163 p. 